\title{
PRELIMINARY FINITE ELEMENT ANALYSIS OF LOCOMOTIVE CRASHWORTHY COMPONENTS
}

\author{
Patricia Llana \\ Volpe National Transportation Systems Center \\ US Department of Transportation \\ Cambridge, MA 02142 USA \\ Richard Stringfellow \\ TIAX LLC \\ Lexington, MA 02421 USA
}

\begin{abstract}
The Office of Research and Development of the Federal Railroad Administration (FRA) and the Volpe Center are continuing to evaluate new technologies for increasing the safety of passengers and operators in rail equipment. In recognition of the importance of override prevention in train-totrain collisions in which one of the vehicles is a locomotive, and in light of the success of crash energy management technologies in cab car-led passenger trains, the Volpe Center seeks to evaluate the effectiveness of components that could be integrated into the end structure of a locomotive that are specifically designed to mitigate the effects of a collision and, in particular, to prevent override of one of the lead vehicles onto the other. A research program is being conducted that aims to develop, fabricate and test two crashworthy components for the forward end of a locomotive: (1) a deformable anti-climber, and (2) a push-back coupler. Preliminary designs for these components have been developed. This paper provides details on the finite element models of the crashworthy components and how the component designs behave in the finite element analyses. The component designs will be evaluated to determine if the requirements have been met, such as the energy absorption capability, deformation modes, and force/crush characteristics.
\end{abstract}

\section{INTRODUCTION}

In the event of a collision between two trains, a considerable amount of energy must be dissipated. One of the potential consequences of such a collision is override of one of the vehicles onto the other. Locomotives, because of their great longitudinal strength and stiffness, are particularly susceptible to override when they collide with another vehicle, and the consequences can be catastrophic. Research has shown that conventional anti-climbing structures can deform on impact and form a ramp, increasing the likelihood of override [1]. As they crush longitudinally, conventional anti-climbers lose their vertical load carrying capacity due to the substantial fracture that occurs as the anti-climber crushes. The longitudinal crush of the anti-climber causes fracture in the webs behind the face of the anti-climber. These fractured webs can still resist a longitudinal compression load, but can no longer transmit a vertical shear load. This loss of vertical load-carrying capacity in conventional anti-climbers often leads to ramp formation, which promotes override. Such behavior was exhibited in a head-on collision that occurred in West Eola, Illinois on January 20, 1993. As seen in Figure 1, the accident resulted in one locomotive (right side of photo) overriding the other locomotive, crushing the operator's cab. The photograph shows the overriding locomotive lifted off of its lead truck. In order to be effective, an anti-climber must engage the end structures of opposing equipment and provide sufficient vertical load capacity to prevent such override.

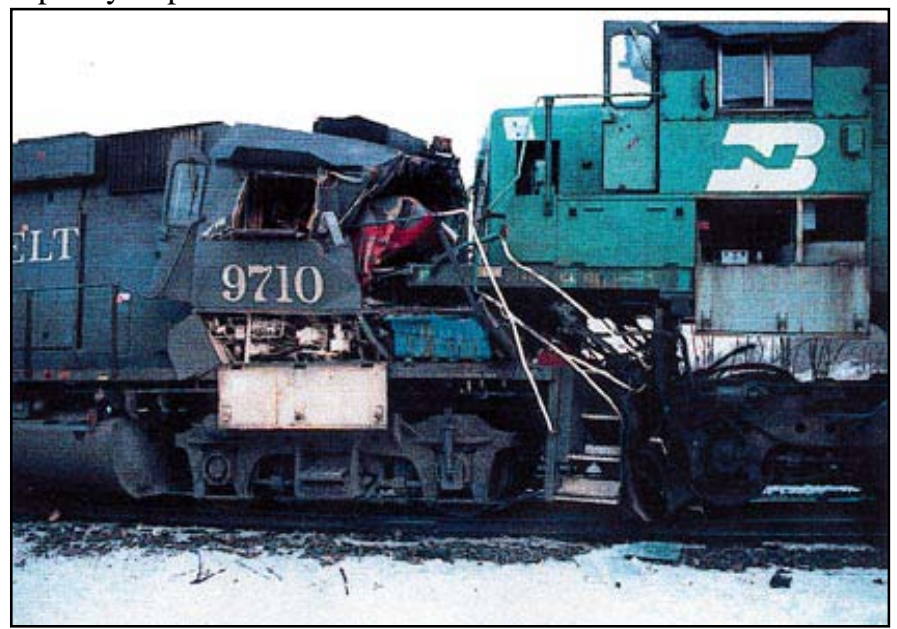

Figure 1. West Eola, Illinois Head-On Collision, January 20, 1993 [1]. 
Research has also shown that the addition of a few structural features to the forward end of a locomotive can greatly reduce the propensity for override [2]. These features include the following:

1. Push-back couplers, and

2. Deformable anti-climbers.

Push-back couplers allow the ends of the vehicles to engage prior to the build-up of large forces and moments that might lead to lateral buckling of the vehicles with respect to one another. Deformable anti-climbers provide sufficient vertical load carrying capacity as they deform gracefully and predictably to prevent the formation of a ramp. Crushable zones within deformable anti-climbers absorb collision energy so as to prevent uncontrolled deformation of interlocking features that might cause formation of a ramp.

Structural features such as these that are specifically put in place to mitigate the effects of a collision are common in rail vehicles that are designed according to the principals of crash energy management (CEM). CEM is a design strategy aimed at increasing occupant survivability during a collision, and is based on the notion that the energy of a collision can be dissipated in a controlled manner through the use of crush zones and other structural features. The Volpe Center is supporting the Office of Research and Development of the FRA in the development of a CEM system for locomotives. In a previous research program, the Volpe Center developed several concepts for a more crashworthy locomotive [2]. The study addressed the feasibility of incorporating push-back couplers and deformable anti-climbers into locomotives. Conceptual design goals included the preservation of occupant volume and the maintenance of vehicle-rail contact, i.e., the prevention of override, while ensuring that the equipment was compatible with existing operating requirements. Building on this previous work, the objectives of the current research program are to: (1) develop detailed designs for a push-back coupler and a deformable anti-climber; (2) develop test article designs for the components; (3) construct the test articles; (4) conduct the component tests; and (5) refine the designs based on the results of the tests. The preliminary development of the component designs has been conducted and is detailed in a companion paper [3].

\section{DESIGN REQUIREMENTS}

The first phase of the research program was aimed at defining design requirements for a platform-style locomotive with increased crashworthiness due to the incorporation of a pushback coupler and deformable anti-climber. These requirements govern the development of designs for push-back coupler and deformable anti-climber components, and include collision scenarios for evaluating their behavior in a collision with another vehicle. The design requirements are comprised of performance requirements, geometric requirements, operational requirements, and fabrication requirements. The energy absorption requirements and many of the other crashworthiness specifications are derived from experience gained in other crashworthiness programs. Most of the strength requirements and some of the crashworthiness specifications are derived from the APTA [4] and AAR [5] standards. All of the requirements are consistent with CFR 49, Part 229 [6], APTA SS-C\&S-034-99, Rev 2 [4], and APTA RP-C\&S-XXX [7]. During the development process, the design requirements undergo slight modification as the designs are evaluated. The current design requirements are listed here. They vary slightly from those listed in the companion paper [3].

\section{Performance Requirements \\ Push-back Coupler}

- Trigger mechanism: shear bolt or deformation tube arrangement

- Trigger load: minimum 600,000 lbf/maximum 800,000 lbf

- Push-back enables end frames of colliding equipment to engage

- Stroke: The push-back coupler must be capable of pushing back with enough stroke to accommodate and capture conventional locomotive, cab car and freight car couplers. The minimum will be based on interaction with cab and freight cars, and the maximum based on open space behind draft pocket.

- Energy absorption: must absorb energy in a controlled manner while pushing back; minimum 600,000 ft-lbf (based on stroke and load characteristics)

- Support structure: no permanent deformation prior to exhaustion of push-back coupler stroke; crippling load of support structure must not be exceeded in a $12 \mathrm{mph}$ impact into another consist

- Torsional resistance: minimum 150,000 ft-lbf prior to pushback and after exhaustion of push-back function

- Retention: must be strong enough to support a draft load of $150,000 \mathrm{lbf}$ at any time during push-back and after exhaustion of push-back function

- No material failure (material separation)

Deformable Anti-climber

- Trigger mechanism: plastic deformation/progressive buckling of energy absorbers

- Stroke: minimum 10 inches (based on operational requirements, geometric requirements, and interaction with cab and freight cars)

- Energy absorption: minimum 600,000 ft-lbf (based on stroke and load characteristics)

- Vertical strength: 100,000 lbf in both un-deformed and fully-deformed configurations

- Support structure: strong enough to support crush load without failing or undergoing large plastic deformation; crippling load of support structure must not be exceeded in a $12 \mathrm{mph}$ impact into another consist

- No material failure (no separation); highly localized material failure will be permitted so long as it does not affect the repeatability of anti-climber crush behavior

\section{Collision Scenarios}

A locomotive design featuring the two crashworthy components developed in this program would necessarily be placed in

This material is declared a work of the U.S. Government and is not subject to copyright protection in the United States. Approved for public release; distribution is unlimited. 
service along with conventional equipment. For this reason, the consequences of three different collision scenarios must be evaluated:

1. Modified locomotive to conventional locomotive

2. Modified locomotive to cab car

3. Modified locomotive to freight car

The collision speed for each scenario will be defined so as to exhaust the stroke of both the deformable and push-back coupler energy absorption systems and initiate loading of the locomotive underframe. Each scenario will be evaluated for three conditions:

1. Vehicles perfectly aligned

2. Modified locomotive offset upward by 6.0 inches

3. Modified locomotive offset downward by 6.0 inches

Performance in each scenario will be evaluated through largedeformation dynamic finite element analysis (FEA). The following criteria shall be used to evaluate satisfaction of the requirements relative to the collision scenarios:

- No override of one vehicle onto another

- No formation of a ramp that might eventually lead to override

- No uncontrolled deformation in modified locomotive

- No uncontrolled deformation in conventional vehicles

- A best-fit straight line approximation of the force/crush data shall exhibit a positive slope until the crush for the crashworthy components is exhausted and the underframe begins to crush.

- The strength of the underframe shall be at least 50\% higher than the crush strength of the combined deformable anticlimber/push-back coupler system.

- The underframe must be strong enough to support the loads on the deformable anti-climber and push-back coupler without undergoing large deformation.

\section{Geometric Requirements Push-back Coupler}

- Cannot interfere with existing locomotive structures during and following push-back to its complete stroke

\section{Deformable Anti-climber}

- Width: must extend laterally, at a minimum, to the approximate $1 / 3$ points across the width of the end of the locomotive; must also extend laterally to the main longitudinal beams of the locomotive

- Depth: center must extend to within 4 inches of the pulling face of the coupler with the draft gear fully compressed and must extend no less than 10" from the locomotive front plate for its required width

- Cannot interfere with other equipment, unless it is agreed that such equipment can be easily re-routed

\section{Operational Requirements}

- Low-speed coupling: The push-back coupler system must be able to withstand a hard couple between two locomotives at a speed of $5 \mathrm{mph}$ without triggering the push-back system.
- Curving: The components of the locomotive shall not interfere for operation with nominally identical vehicles operating on curves up to 23 degrees.

\section{Fabrication Requirements General}

- The design should utilize materials and fabrication methods that a normal metal fabrication company could use.

\section{Materials}

- The materials of construction for the primary structure and the energy absorbing elements shall be either high strength low alloy (also known as low-alloy, high tensile) or austenitic stainless steels commonly used in the fabrication of modern railway vehicles for operation in North America. Aluminum honeycomb may be used for energy absorbers.

\section{Construction Methods}

- All primary structural members shall be welded in accordance with AWS D1.1. Bolting may be used for the push-back coupler trigger mechanism.

\section{Overall Vehicle Integration}

- The push-back coupler and deformable anti-climber components shall be designed so that they can be integrated onto an existing passenger locomotive.

\section{COMPONENT DESIGNS}

\section{Deformable Anti-climber}

The specific locomotive platform chosen for development is a MotivePower MPXpress MP40PH-3C. The design for the deformable anti-climber employs four progressive buckling tubes (crush tubes) welded onto the front plate of the locomotive: two tubes located at the base of the short hood, and two tubes located beneath them. Figure 2 shows a detailed view of the deformable anti-climber/pushback coupler system.

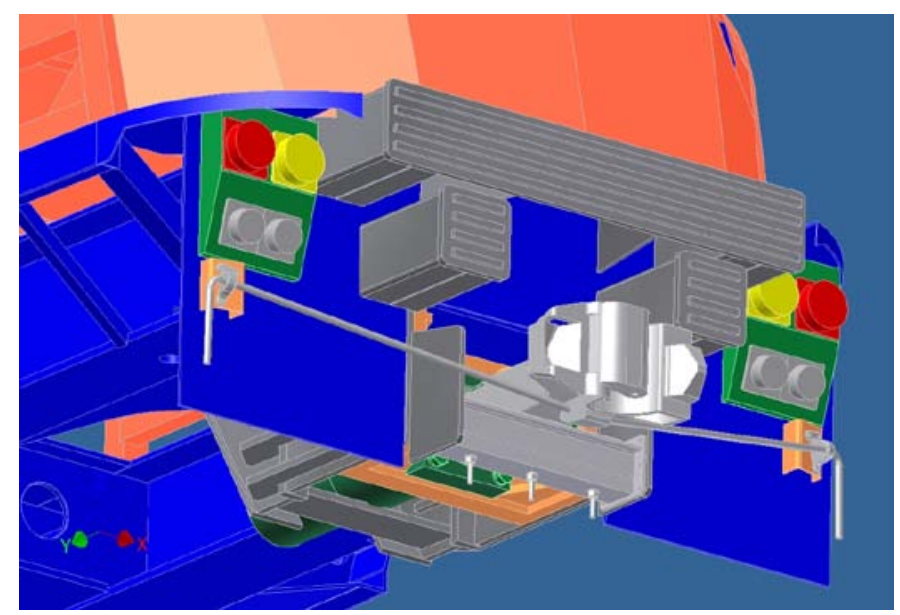

Figure 2. Detailed view of the deformable anticlimber/push-back coupler system.

In a collision with a conventional locomotive, the upper crush tubes are designed to interact with heavy gussets that are welded to the front plate of the locomotive as part of the conventional anti-climber. The upper crush tubes are connected

This material is declared a work of the U.S. Government and is not subject to copyright protection in the United States. Approved for public release; distribution is unlimited. 
laterally by a ribbed front plate. This plate is designed to resist the upward motion of the coupler of a colliding vehicle to help prevent override. Together with the upper set of crush tubes, it is designed to withstand a 100,000 lbf vertical load at any time during the crush process. In the event of a collision with a cab car, this plate also interacts with the collision posts at the end of the cab car, allowing the upper crush tubes to absorb energy. The lower set of crush tubes is designed to interact with the buffer beam of a colliding cab car. In a collision with a conventional locomotive, these tubes do not participate in the early stages of the collision. In a collision with a center beam flat car-type freight car, neither set of tubes participates in the early stages of the collision. Eventually, they interact with the bulkhead of the freight car.

Support structures have been added between the two main longitudinal beams of the underframe for the purpose of transferring impact loads into the underframe, as shown in Figure 3.

\section{Push-back Coupler}

The design for the push-back coupler employs an H-type coupler attached to a push-back yoke and deformation tube. Figure 4 shows a view from below of the push-back coupler inside the draft gear pocket of the locomotive. The draft gear pocket has been redesigned to provide more than 10 inches of additional stroke. The push-back coupler is attached to the draft gear pocket by the coupler support assembly (shown in yellow in Figure 4) with 12 shear bolts, six on each side. The six shear bolts on the right side are shown in Figure 5 in green. These bolts are designed to fail at a total load of approximately $1,000,000 \mathrm{lbf}$ once the energy-absorbing stroke of the pushback coupler has been exhausted, thereby shifting the load path from the push-back coupler to the deformable anti-climber.

After the shear bolts fail, the entire coupler support assembly, or 'sliding lug', slides back, so that the load through the coupler is effectively zero. As is shown in Figure 5, the back of the draft pocket has structure built into it that will capture the sliding lug after 10 additional inches of push-back.

\section{FINITE ELEMENT MODELS}

Finite element (FE) meshes were constructed for the conventional and modified locomotives, a cab car, and a freight locomotive. These meshes were appropriately combined to form the basis of finite element models for the three collision scenarios described in the design requirements. All of the FE models are symmetric about a vertical-longitudinal plane.

\section{Conventional Locomotive Model}

A computer-aided design (CAD) model of the MPXpress MP40 locomotive was generously provided by MotivePower. The FE model of the vehicle, which features a mix of shell elements and beam elements, was created using the software program ABAQUS/CAE. The model is depicted in Figure 6. A total of approximately 50,000 mostly shell elements are used. The mesh was refined progressively from the rear end of the vehicle to the forward end, with the characteristic element size decreasing from four inches to one-half inch.

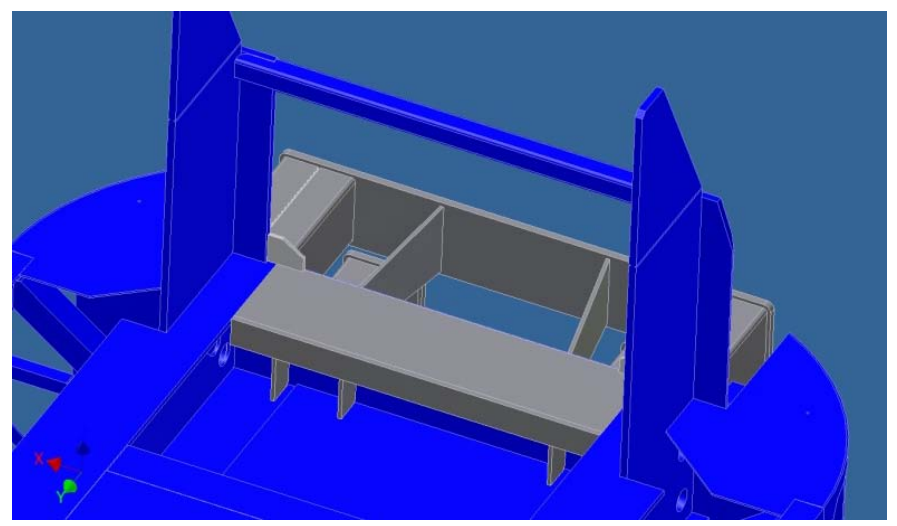

Figure 3. Deformable anti-climber (grey) and existing structure (blue).

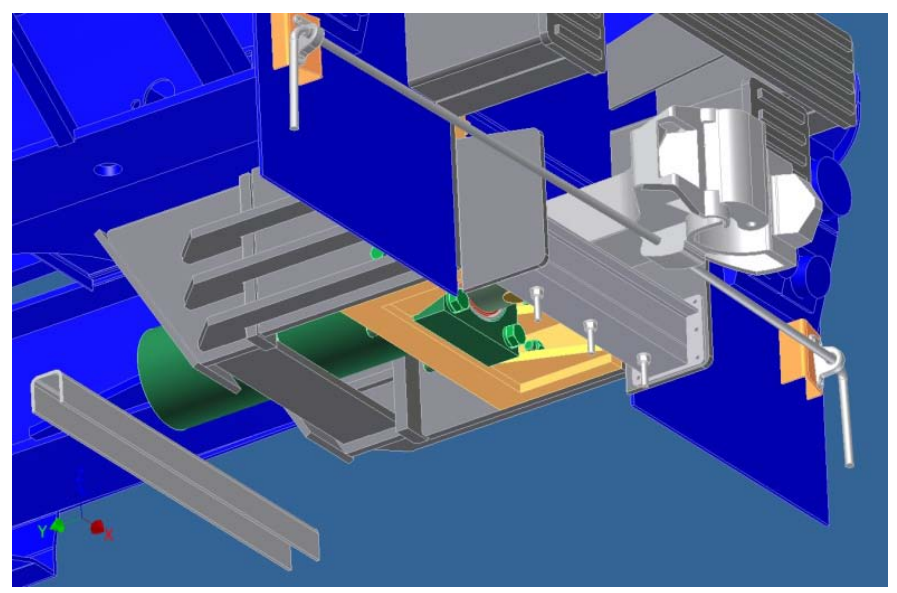

Figure 4. Bottom view of push-back coupler.

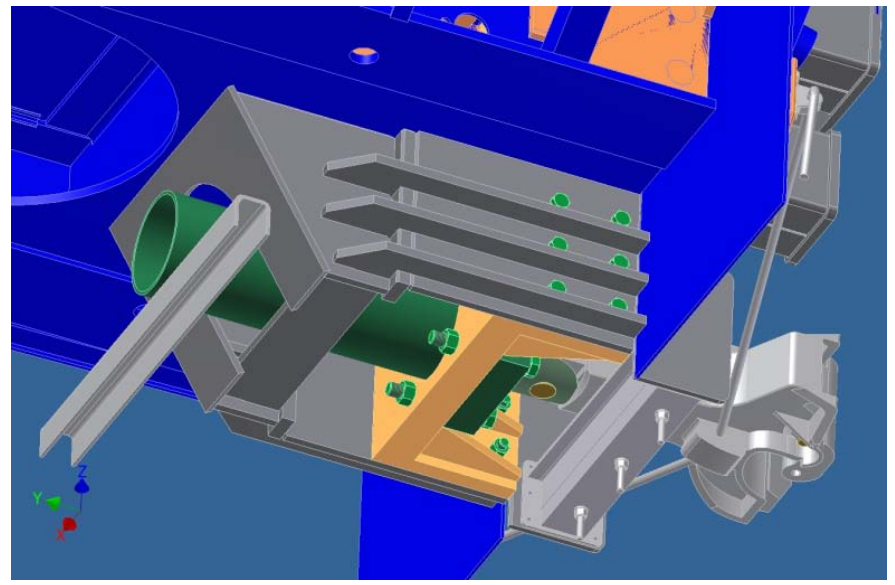

Figure 5. View of the shear bolts (green) that attach the push-back coupler to the sides of the draft gear pocket.

The trucks were modeled as rigid bodies. Connector elements were used to tie the trucks to the underframe of the vehicle at the bolsters. Likewise, the coupler was modeled as a

This material is declared a work of the U.S. Government and is not subject to copyright protection in the United States. Approved for public release; distribution is unlimited. 
rigid body tied to the draft pocket by means of a longitudinallyoriented connector element. The engine/long hood and fuel tank were also modeled as rigid bodies. The total weight of the vehicle was set to approximately 290,000 lbf. Figure 7 shows a detail of the forward end of the model.

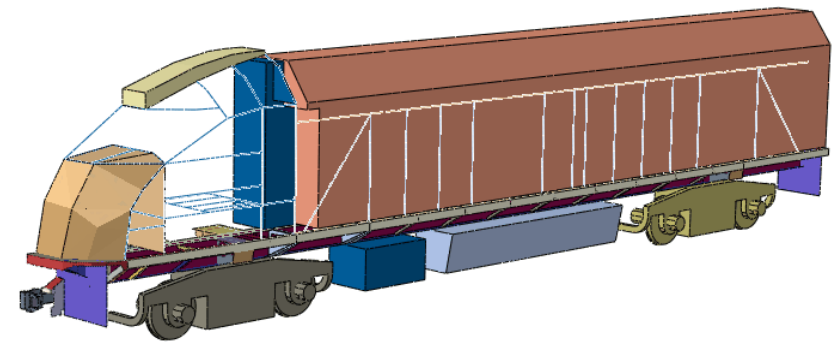

Figure 6. FE model for the conventional locomotive.

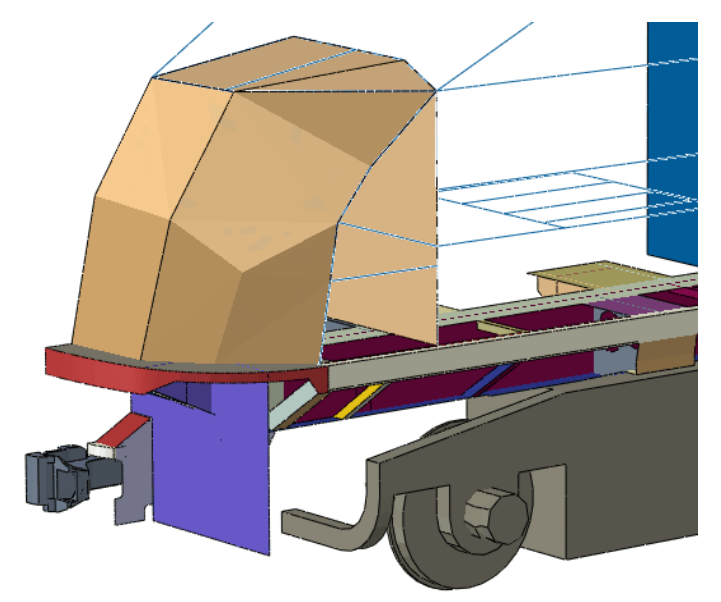

Figure 7. FE model for the conventional locomotive (detail of forward end).

\section{Modified Locomotive Model}

The FE model for the modified locomotive (Figure 8) was constructed in a similar manner, using a CAD model that was derived from the CAD model of the conventional MP40 locomotive, and incorporates modifications to that model that were made to integrate the two crashworthy components. The model has approximately 94,000 elements, with progressive element refinement toward the forward end of the vehicle. The crush elements feature a characteristic element size of 0.25 inches.

The push-back coupler is represented as a rigid body that is tied using longitudinally-oriented connector elements to the sliding lug. The connector is defined to be elastic-plastic, with a plateau crush force of 674,000 lbf. The sliding lug is also modeled as a rigid body. The twelve bolts that tie the sliding lug to the side of the draft pocket are represented as rigid bodies tied with a connector element that models the build-up of load to 88,000 lbf in each bolt, and the subsequent failure of the bolt over 0.1 inches of additional displacement.

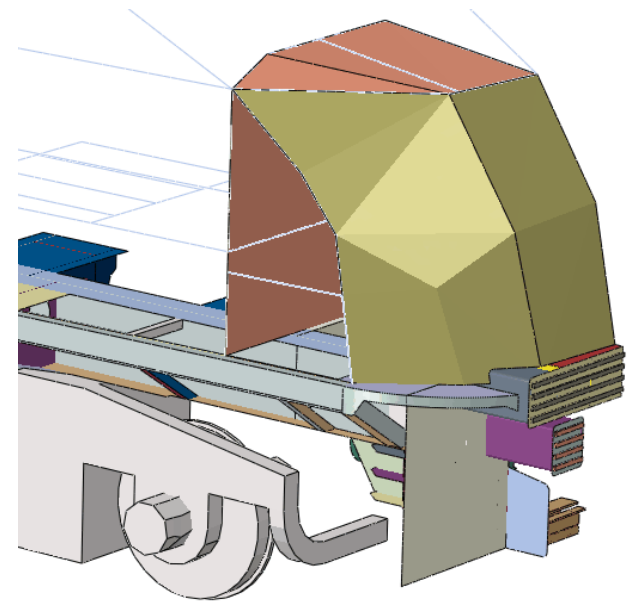

Figure 8. FE model for the modified locomotive (detail of forward end).

\section{Cab Car Model}

The FE Model for the cab car (shown in Figure 9 and Figure 10) was constructed by modifying a model of a Budd M1 cab car developed in a previous program [8]. In particular, the collision posts were moved forward to within one-half inch of the front face of the buffer beam to more adequately represent the typical cab car collision post location. The model contains approximately 80,000 mostly shell elements, with beam elements used to model some of the stiffening structures in the passenger compartment roof and side walls. The refinement of the mesh again increases progressively toward the front of the vehicle.

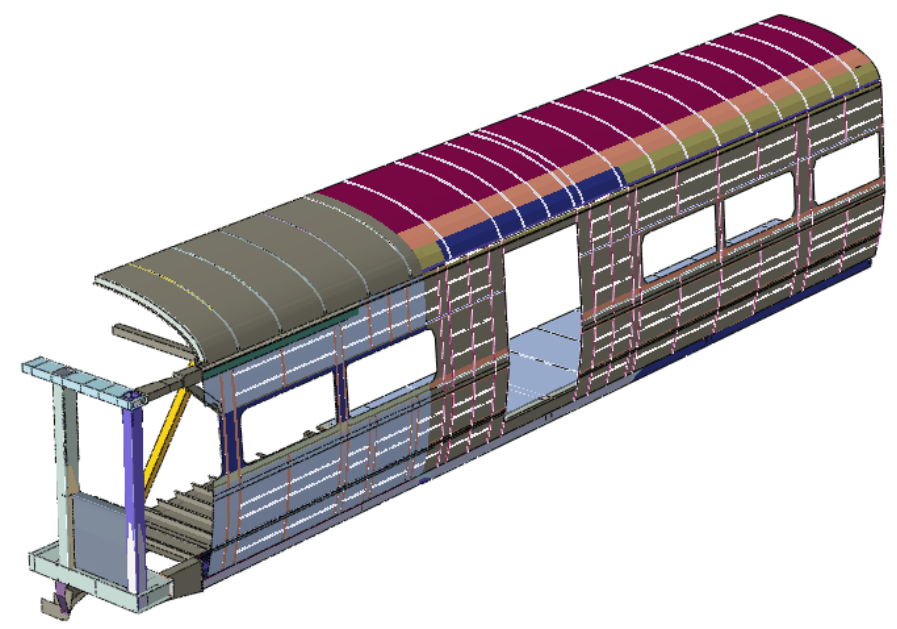

Figure 9. FEA model for the cab car.

Only the forward half of the car is modeled; the nodes along the center lateral/vertical plane of the car are completely constrained. The forward truck is modeled as a rigid body, tied to the underframe of the vehicle at the bolster using connector elements. The coupler (not shown in Figure 9 or Figure 10) is also modeled as a rigid body, with a longitudinally-oriented connector element used to represent draft gear compression.

This material is declared a work of the U.S. Government and is not subject to copyright protection in the United States. Approved for public release; distribution is unlimited. 


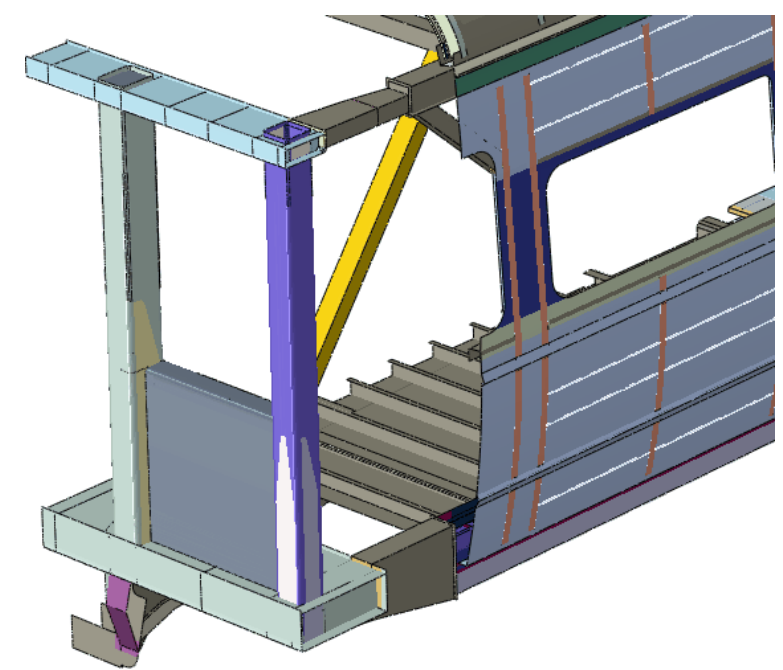

Figure 10. FEA model for the cab car (detail of forward end).

\section{Freight Car Model}

A center beam flat car-type freight car model (see Figure 11) was constructed in ABAQUS/CAE using two-dimensional drawings generously provided by TrinityRail. The model uses approximately 53,000 shell elements, with a characteristic element size of 1.5 inches.

Like the cab car model, only the forward half of the car is modeled; the nodes along the center lateral/vertical plane of the car are completely constrained. The forward truck is modeled as a rigid body, tied to the underframe of the vehicle at the bolster using connector elements. The coupler/cushion unit (not shown in Figure 11) is also modeled as a rigid body, with a longitudinally-oriented connector element used to represent cushion unit compression.

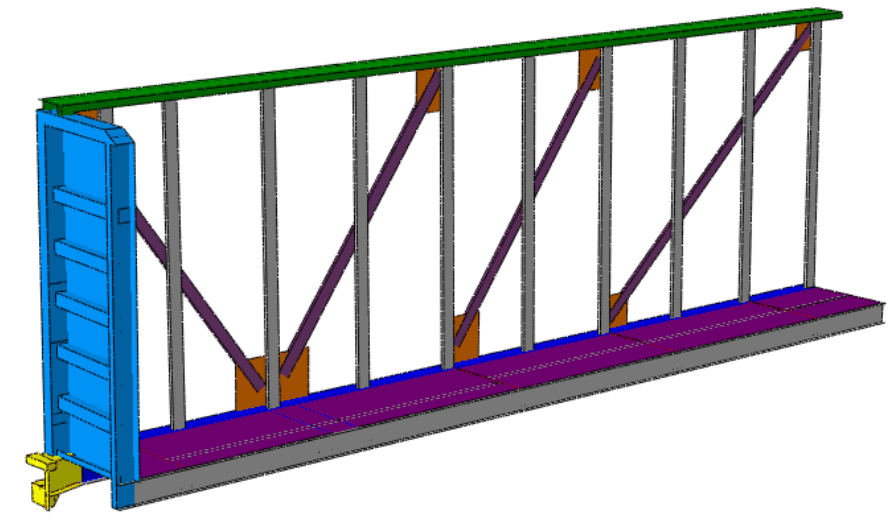

Figure 11. FEA model for the freight car

\section{FINITE ELEMENT ANALYSIS RESULTS}

The component designs were evaluated against the design requirements using explicit dynamic FEA in order to assess their performance in the collision scenarios. The ABAQUS/Explicit FEA code (version 6.8.1) was used to conduct the analyses. As stated in the design requirements, the consequences of three collision scenarios were evaluated:

1. Modified locomotive to conventional locomotive

2. Modified locomotive to cab car

3. Modified locomotive to freight car

Each scenario was evaluated for three conditions:

1. Vehicles perfectly aligned (baseline)

2. Modified locomotive offset upward by 6.0 inches

3. Modified locomotive offset downward by 6.0 inches For each collision scenario, several results for the baseline case in which the vehicles are aligned are described below. In addition, the force-displacement results for the three collision conditions for each case are compared.

\section{Modified Locomotive to Conventional Locomotive}

The results of the simulation of a $20 \mathrm{mph}$ collision of the modified locomotive and a conventional locomotive are summarized in Figure 12 through Figure 15. The 20 mph speed was chosen to provide enough kinetic energy to the system to bring it to the point where both the push-back coupler and anticlimber strokes were exhausted. An annotated force versus displacement curve is shown in Figure 12. In this curve (as in all of the force-displacement curves calculated for the collision scenarios), displacement is calculated as the relative motion of the centers of the respective vehicles toward one another. In the collision simulation, the force builds up to the $674,000 \mathrm{lbf}$ load of the push-back coupler, and then levels off. The travel of the deformation tube element of the coupler is exhausted after approximately 19 inches of crush, and the load quickly builds up to the point where the shear bolts fail.

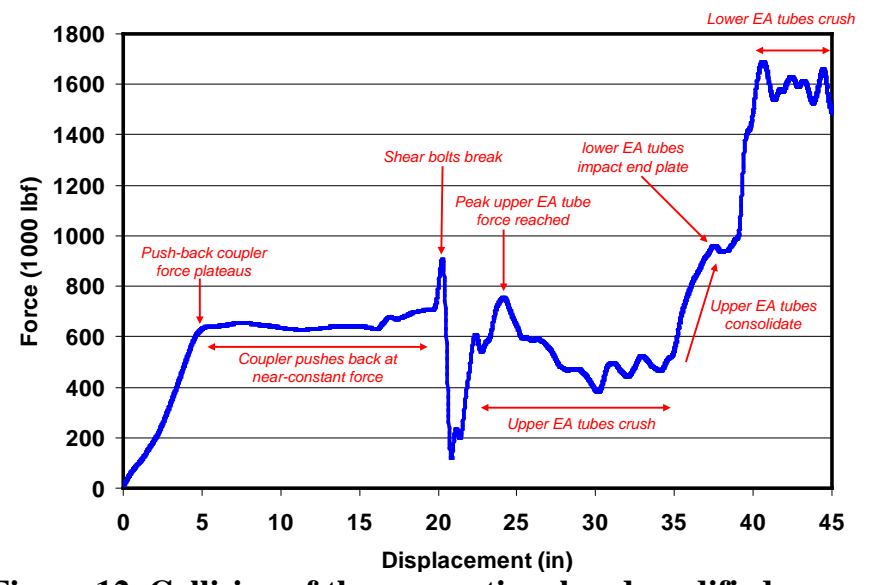

Figure 12. Collision of the conventional and modified locomotives: annotated force versus displacement curve for in-line case.

As the bolts break, there is a sharp drop in load, and then the load builds up again as the upper/outer crush tubes begin to interact with the gusset plates and other structures at the front of the conventional locomotive. A second peak in load of about $760,000 \mathrm{lbf}$ occurs after about 24 inches of total crush, and then the load settles into a range of between 400,000 and 600,000 lbf

This material is declared a work of the U.S. Government and is not subject to copyright protection in the United States. Approved for public release; distribution is unlimited. 
as these tubes crush. After about 34 inches of crush, the upper tubes begin to consolidate, and the load rises. After 38 inches of crush, the lower/inner crush tubes impact the front plate of the conventional locomotive, and the load rises further, eventually reaching 1.7 million lbf before settling into a second pattern of crush at a load range of between 1.5 million and 1.7 million lbf.

Figure 13 and Figure 14 illustrate the deformation that arises as the vehicles crush. Consistent with the forcedisplacement results, after 31 inches of crush (Figure 13) only the upper tubes have crushed. There is also a significant extent of deformation in the anti-climber of the conventional locomotive, but little or no deformation in either vehicle behind the front plate. After 45 inches of crush (Figure 14) the load is about 1.5 million lbf, and the underframe of the locomotives have begun to crush, as has the lower set of crush tubes.

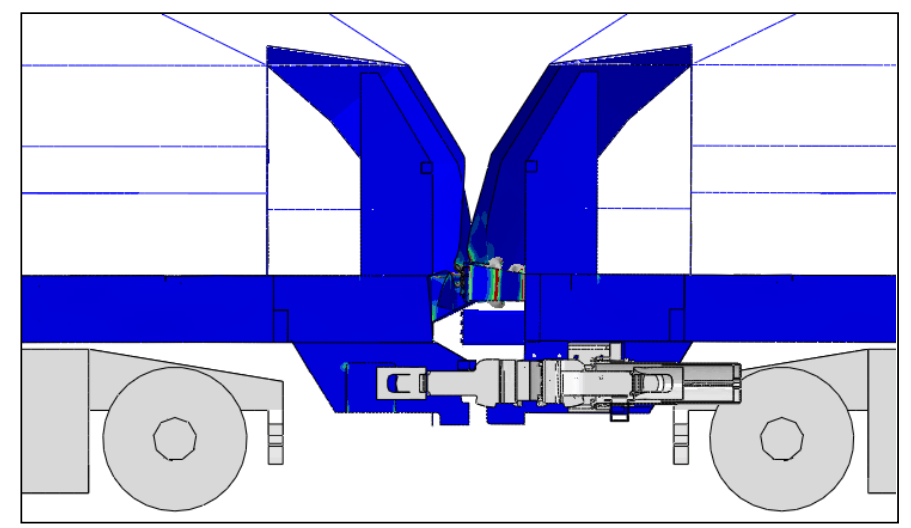

Figure 13. Collision of the conventional and modified locomotives: side view showing crush of vehicles after 31 inches of crush.

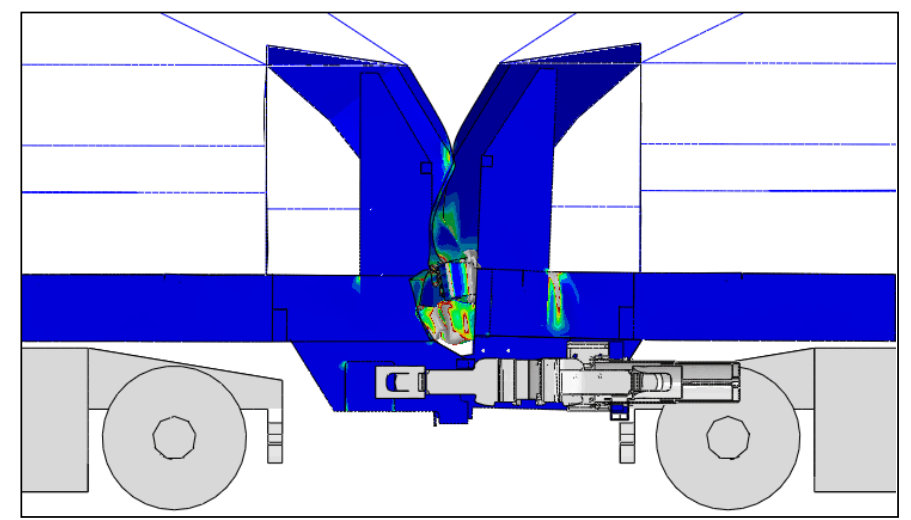

Figure 14. Collision of the conventional and modified locomotives: side view showing crush of vehicles after 45 inches of crush.

When the vehicles are misaligned vertically, there is a drop-off in the crush performance for this scenario, as expected. The force displacement curves for the in-line and offset cases are compared in Figure 15. The drop-off in performance appears to be worse for the case in which the modified locomotive is lowered by six inches. For this case, the interaction of the upper deformation tubes with the gussets and other structures forward of the end plate of the conventional locomotive is not as clean, and the mode of deformation of the tubes is less desirable.

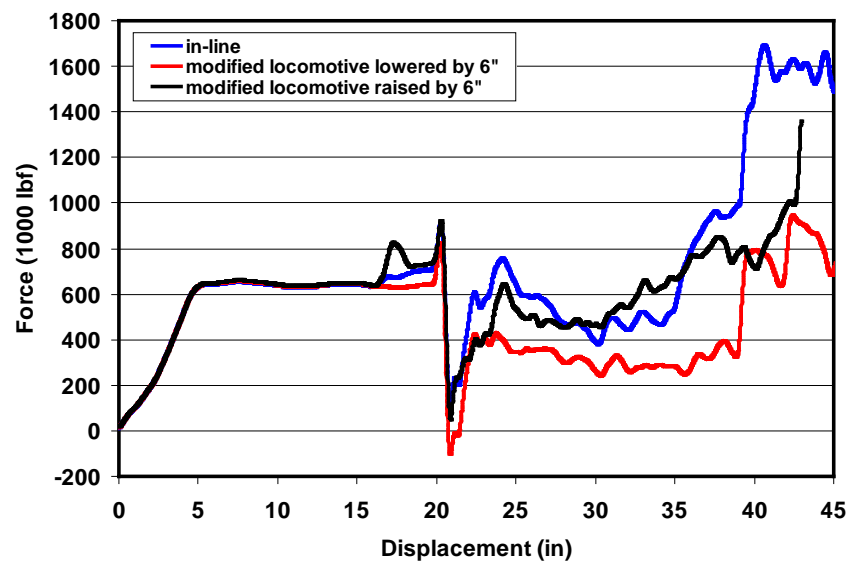

Figure 15. Collision of the conventional and modified locomotives: comparison of force-displacement curves for in-line and offset cases

The extent of energy absorption for these three cases is summarized in Table 1 . The table shows the energy absorption levels when the load reaches 1.2 million lbf. For all of the cases, the energy absorption target of $600,000 \mathrm{ft}-\mathrm{lbf}$ for the coupler element is easily met. The energy absorption target of $600,000 \mathrm{ft}-\mathrm{lbf}$ for the anti-climber element is met only for the baseline, in-line case. For the case in which the modified locomotive is raised by six inches, the loss of energy absorption in the anti-climber appears to be more than compensated by the additional energy absorption that occurs in the conventional locomotive structures. This is not true for the case in which the modified locomotive is lowered by six inches; however, the total energy absorption is still quite extensive. For this case, the force never reaches 1.2 million lbf. The first value in the table is when the locomotive underframes begin to show significant plastic deformation, and the second value is at the end of the analysis. For each of these analyses, there is no uncontrolled deformation of modified or conventional locomotive structures before the load reaches 1.2 million lbf.

Table 1. Collision of the conventional and modified locomotives: comparison of energy absorption levels (ftkips).

\begin{tabular}{|l|c|c|c|}
\hline & Baseline (In-Line) & $\begin{array}{c}\text { Modified Loco. } \\
\text { Raised by 6" }\end{array}$ & $\begin{array}{c}\text { Modified Loco. } \\
\text { Lowered by 6" }\end{array}$ \\
\hline Push-back Coupler & 922 & 923 & 925 \\
\hline Anti-climber & 652 & 452 & $350 / 706$ \\
\hline $\begin{array}{l}\text { Other Modified } \\
\text { Locomotive Structures }\end{array}$ & 45 & 26 & $86 / 186$ \\
\hline $\begin{array}{l}\text { Conventional } \\
\text { Locomotive Structures }\end{array}$ & 273 & 694 & $110 / 155$ \\
\hline Total & 1,892 & 2,095 & $1,471 / 1,972$ \\
\hline
\end{tabular}

This material is declared a work of the U.S. Government and is not subject to copyright protection in the United States. Approved for public release; distribution is unlimited. 


\section{Modified Locomotive to Cab Car}

The results of the simulation of a $20 \mathrm{mph}$ collision of the modified locomotive into a cab car are summarized in Figure 16 through Figure 19. An annotated force versus displacement curve is shown in Figure 16. The first part of the force-crush curve is essentially the same as it is for the modified locomotive/conventional locomotive collision. The force builds up to $674,000 \mathrm{lbf}$, levels off, and when the push-back coupler deformation tube travel is exhausted after 19 inches of crush, quickly builds up until the shear bolts fail.

The response following bolt failure is different. The sharp drop in force is followed by a steep rise in force when the lower/inner crush tubes impact the buffer beam. The force levels off for several inches and then drops to about 400,000 lbf after 27 inches of crush, whereupon the upper/outer crush tubes impact the collision posts and bulkhead of the cab car. The force then gradually increases to about 1.25 million lbf after about 38 inches of crush, before dropping again as the cab car draft sill begins to buckle.

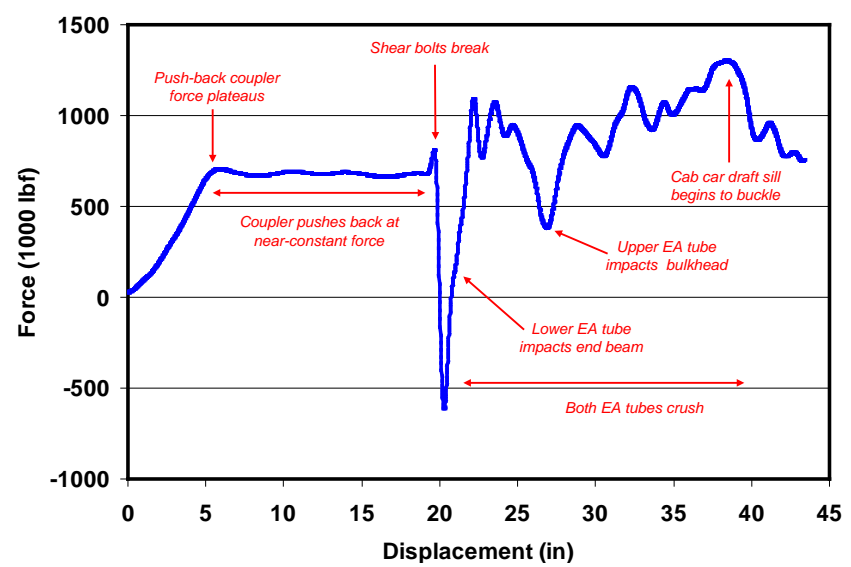

Figure 16. Collision of the modified locomotive and a cab car: annotated force versus displacement curve for in-line case.

Figure 17 and Figure 18 illustrate the deformation that arises as the vehicles crush. After 31 inches of crush (Figure 17) all of the tubes are crushing. Most of the deformation is occurring in the deformable anti-climber, with some deformation of the forward end of the cab car (side sills, roof sills and bulkhead) and some deformation of other locomotive end structures (notably, the short hood). After 43 inches of crush (Figure 18) the force has dropped from its peak value of 1.25 million lbf, and the underframe of the cab car has begun to buckle.

When the vehicles are misaligned vertically, there does not seem to be as much of a drop-off in the crush performance for this scenario as compared to the modified locomotive/conventional locomotive collision scenario, as illustrated in Figure 19. In fact, when the modified locomotive is lowered by six inches with respect to the cab car, the force that arises following impact actually increases, because the lower tubes impact the buffer beam more directly, and the impact of the upper tubes with the collision posts/bulkhead is stiffer.

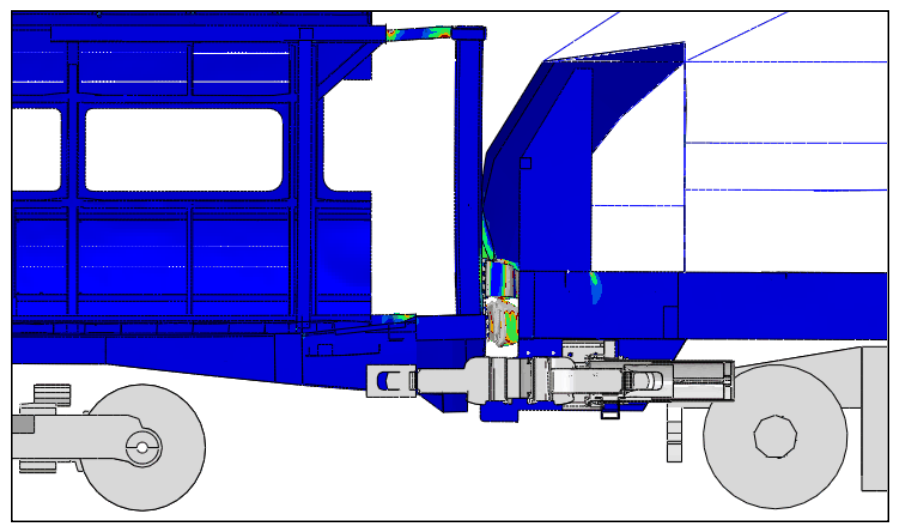

Figure 17. Collision of the modified locomotive and a cab car: side view showing crush of vehicles after 31 inches of crush.

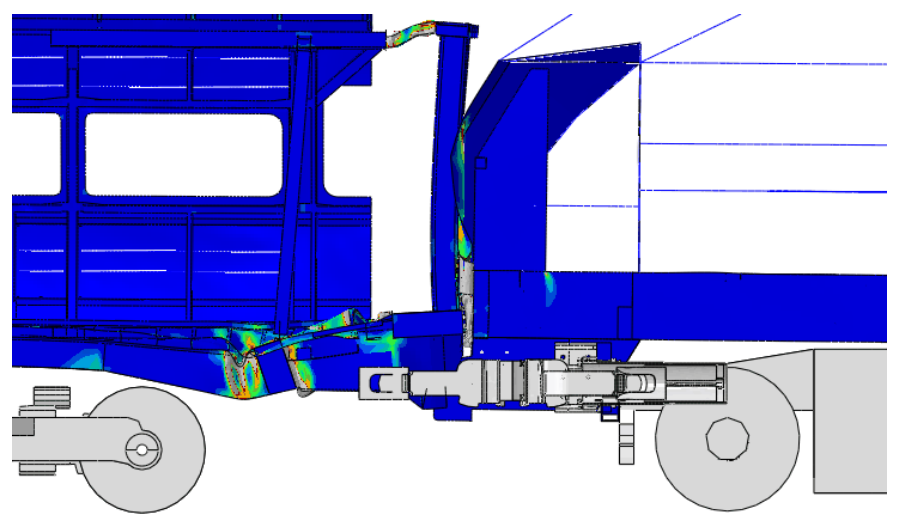

Figure 18. Collision of the modified locomotive and a cab car: side view showing crush of vehicles after 43 inches of crush.

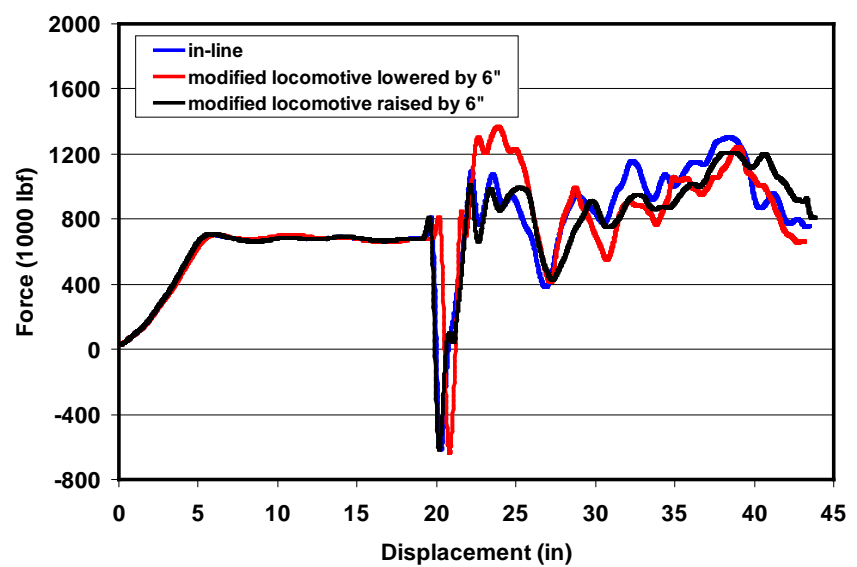

Figure 19. Collision of the modified locomotive and a cab car: comparison of force-displacement curves for in-line and offset cases

This material is declared a work of the U.S. Government and is not subject to copyright protection in the United States. Approved for public release; distribution is unlimited. 
The extent of energy absorption for these three cases is summarized in Table 2. The table shows the energy absorption levels when the load reaches 1.2 million lbf. Again, for all of the cases, the energy absorption target of 600,000 ft-lbf for the coupler element is easily met. The $600,000 \mathrm{ft}-\mathrm{lbf}$ target for the anti-climber is easily met by both the baseline in-line case and the case where the modified locomotive is raised by six inches with respect to the cab car. For the case where the modified locomotive is lowered by six inches with respect to the cab car, the requirement isn't technically met, because the force exceeds 1.2 million by a small extent right at impact of the lower crush tubes and the buffer beam. However, the magnitude of this peak is largely due to the dynamics of the stiff impact, and not reflective of the load transmitted back through the structure to the underframes of the two vehicles. Ignoring this peak, the energy absorption requirement is easily met for this case. For this case, the first value in the table is when the force first exceeds 1.2 million lbf. The second reported value is at maximum force prior to buckling of cab car draft sill, at approximately 39 inches displacement. For each of these analyses, there is no uncontrolled deformation of modified locomotive or cab car structures before 40 inches of crush.

Table 2. Collision of the modified locomotive and a cab car: comparison of energy absorption levels (ft-kips).

\begin{tabular}{|l|c|c|c|}
\hline & Baseline (In-Line) & $\begin{array}{c}\text { Modified Loco. } \\
\text { Raised by 6" }\end{array}$ & $\begin{array}{c}\text { Modified Loco. } \\
\text { Lowered by 6" }\end{array}$ \\
\hline Push-back Coupler & 931 & 933 & 926 \\
\hline Anti-climber & 940 & 774 & $48 / 973$ \\
\hline $\begin{array}{l}\text { Other Modified } \\
\text { Locomotive Structures }\end{array}$ & 95 & 78 & $8 / 138$ \\
\hline Cab Car Structures & 242 & 326 & $75 / 350$ \\
\hline \hline Total & 2,208 & 2,111 & $1,058 / 2,388$ \\
\hline
\end{tabular}

\section{Modified Locomotive to Freight Car}

The results of the simulation of a $20 \mathrm{mph}$ collision of the modified locomotive into a freight car are summarized in Figure 20 through Figure 23. An annotated force versus displacement curve is shown in Figure 20. The first part of the force-crush curve is a little different than it is for the other two cases: the force builds up to and levels off at 600,000 lbf, the assumed crush force of the cushion unit, for the first 15 inches of relative displacement. The force then builds up to 674,000 lbf, the push-back coupler deformation tube force, and remains relatively constant for another 19 inches of crush, whereupon it quickly builds up until the shear bolts fail.

After the bolts fail, the end frames of the two vehicles are still about 18 inches from one another, so there is a period of relative travel at effectively zero force. The anti-climber components then make contact with the end frame and bulkhead wall of the freight car and the load gradually builds up over the next 30 inches to a peak force of 1.2 million lbf, at which the freight car structures begin to collapse.

Figure 21 and Figure 22 illustrate the deformation that arises as the vehicles crush. After 50 inches of crush (Figure
21), the end frames are just approaching one another, but have not yet made contact. After 84 inches of crush (Figure 22) the end structures of the freight car have crushed, together with the anti-climber components, and the forward diagonal support has begun to buckle.

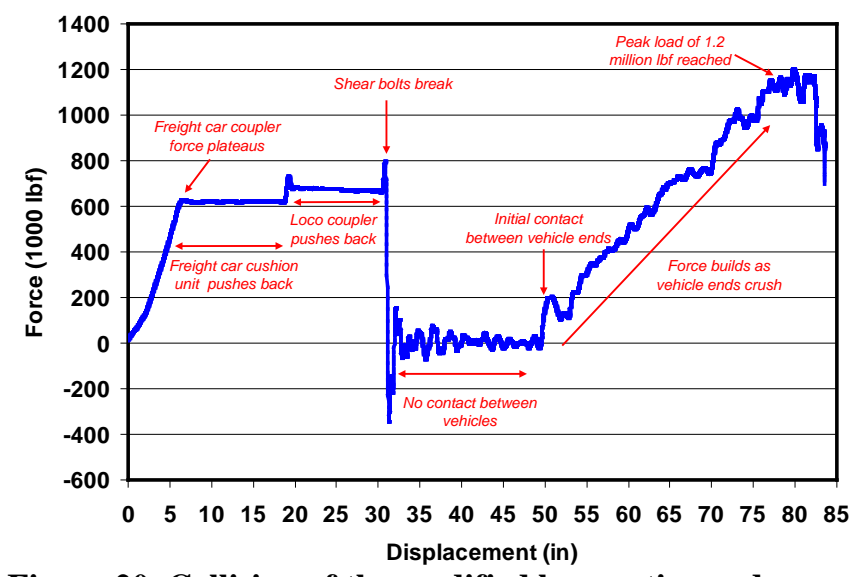

Figure 20. Collision of the modified locomotive and a freight car: annotated force versus displacement curve for in-line case.

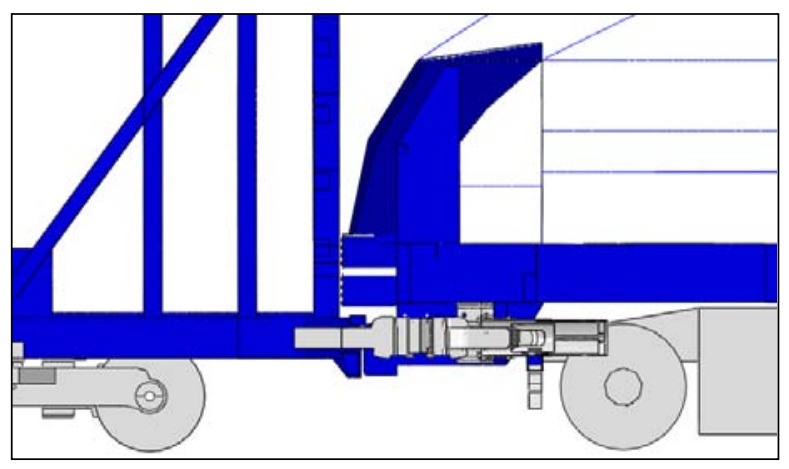

Figure 21. Collision of the modified locomotive and a freight car: side view showing crush of vehicles after $\mathbf{5 0}$ inches of crush.

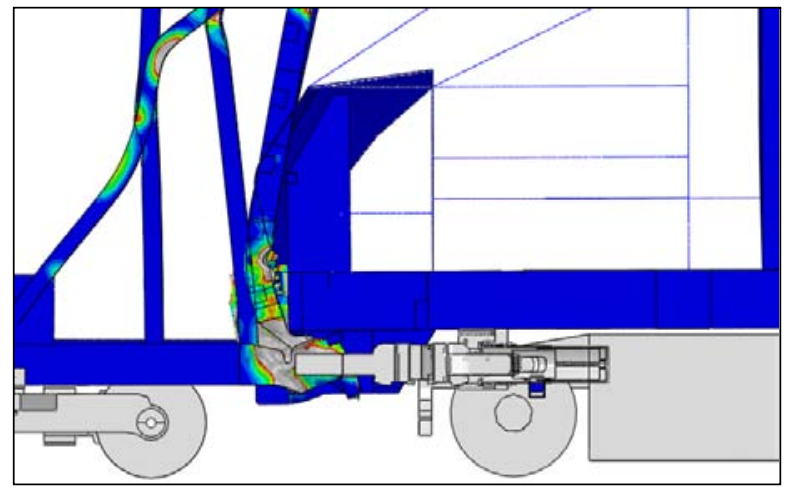

Figure 22. Collision of the modified locomotive and a freight car: side view showing crush of vehicles after 84 inches of crush.

This material is declared a work of the U.S. Government and is not subject to copyright protection in the United States. Approved for public release; distribution is unlimited. 
There again does not seem to be as much of a drop-off in crush performance for this scenario when the vehicles are misaligned vertically, as illustrated in Figure 23. Once again, when the modified locomotive is lowered by six inches with respect to the freight car, the force that arises following impact of the end frames actually increases, because the lower tubes impact the freight car underframe more directly, and the impact of the upper tubes with the bulkhead is stiffer.

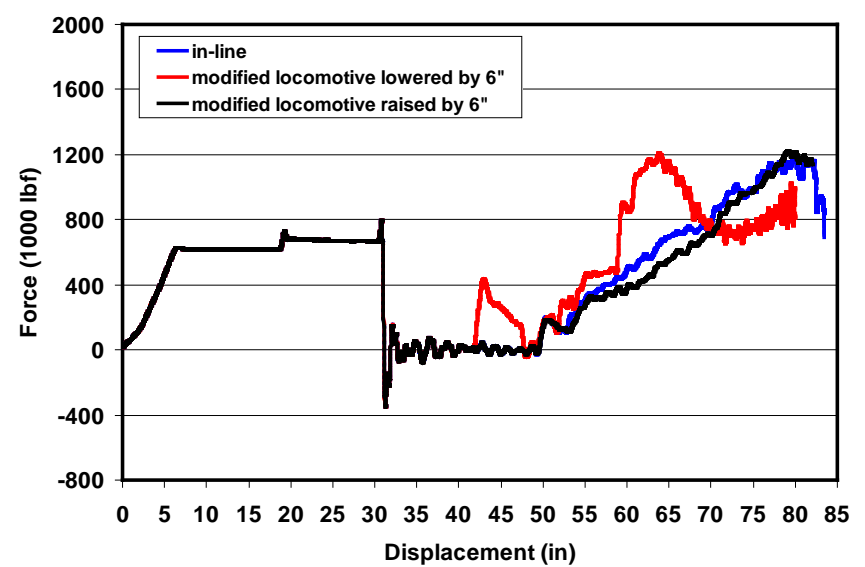

Figure 23. Collision of the modified locomotive and a freight car: comparison of force-displacement curves for inline and offset cases

The extent of energy absorption for these three cases is summarized in Table 3. Again, for all of the cases, the energy absorption target of $600,000 \mathrm{ft}-\mathrm{lbf}$ for the coupler element is easily met. The $600,000 \mathrm{ft}$-lbf target for the anti-climber is not met in any of the cases; however, the cushion unit absorbs nearly 600,000 ft-lbf itself in each case, and the total energy absorbed by the end structure of the freight car is substantial as well. For each of these analyses, there is no uncontrolled deformation of modified locomotive or freight car structures before 80 inches of crush.

Table 3. Collision of the modified locomotive and a freight car: comparison of energy absorption levels (ft-kips).

\begin{tabular}{|l|c|c|c|}
\hline & Baseline (In-Line) & $\begin{array}{c}\text { Modified Loco. } \\
\text { Raised by 6" }\end{array}$ & $\begin{array}{c}\text { Modified Loco. } \\
\text { Lowered by 6" }\end{array}$ \\
\hline $\begin{array}{l}\text { Locomotive Push-back } \\
\text { Coupler }\end{array}$ & 871 & 871 & 871 \\
\hline $\begin{array}{l}\text { Freight Car Cushion } \\
\text { Unit }\end{array}$ & 587 & 586 & 586 \\
\hline Anti-climber & 146 & 105 & 202 \\
\hline $\begin{array}{l}\text { Other Modified } \\
\text { Locomotive Structures }\end{array}$ & 98 & 65 & 82 \\
\hline Freight Car Structures & 1381 & 1209 & 513 \\
\hline \hline Total & 3,083 & 2,836 & 2,254 \\
\hline
\end{tabular}

\section{SUMMARY \& DISCUSSION}

The Volpe Center has developed designs for two components that improve the crashworthiness of locomotives: a deformable anti-climber and a push-back coupler. These designs have been evaluated against the design requirements and have been found to meet a majority of them. The push-back coupler design and deformable anti-climber design meet all of the geometric requirements, the operational requirements, and the fabrication requirements.

The push-back coupler design meets all of its performance requirements. With respect to the key performance metric of energy absorption, the finite element analyses indicate that the push-back coupler component easily satisfies the $600,000 \mathrm{ft}-\mathrm{lbf}$ requirement for all nine collision scenario cases.

The deformable anti-climber meets all of its performance requirements, with one exception. The 600,000 ft-lbf energy absorption requirement was not met for any of the locomotiveto-freight car collision scenarios. For these collision scenarios, the nature of the end structure of the center beam flat car precludes significant interaction of the deformable anti-climber with the end structures of the freight car until significant relative displacement has occurred between the vehicles, approximately 50 inches. When they do begin to interact, the deformable anti-climber structures are stronger than the freight car bulkhead structures, so most of the energy is absorbed in the freight car. The 600,000 ft-lbf energy absorption requirement was met for the modified locomotive-to-cab car collision scenario for all cases. It was also met for the baseline, in-line modified locomotive-to-conventional locomotive collision scenario. For the offset cases, there is a drop-off in anti-climber energy absorption; however, this is offset by additional energy absorption in other end structures.

It is worth noting that, in each of the cases in which the deformable anti-climber 600,000 ft-lbf energy absorption requirement was not met, the overall energy absorption of the vehicle end structures is sizable (see Tables 1, 2 and 3). Also, the 100,000 lbf deformable anti-climber vertical load strength requirement, which is crucial in preventing ramp formation, was not only met, but finite element results indicate that vertical strength levels are at least 300,000 lbf in the deformable anti-climber at all crush levels.

Both components met all of the collision scenario performance requirements. There was no ramp formation or uncontrolled deformation in the modified or conventional vehicles, and, of particular importance, there was no override of one vehicle onto another in any of the collision scenario cases.

\section{NEXT STEPS}

Plans are being developed to test the individual push-back coupler and deformable anti-climber components. This includes designing test article fixtures for both components, building and analyzing finite element models of the test articles and fixtures, and evaluating the results to confirm that their crush behavior faithfully represents the behavior of the draft component designs. The push-back coupler and deformable anti-climber test articles will be sacrificial structures, designed to be dynamically tested, with each component built and tested separately.

Once the test article designs are finalized, the test articles and test fixtures will be fabricated, assembled, and tested.

This material is declared a work of the U.S. Government and is not subject to copyright protection in the United States. Approved for public release; distribution is unlimited. 
Comparisons between the pre-test predictions and the test measurements will be made. The level of performance measured during the test will be compared with the required performance of the components. If there is a large variation in the performance between the component tests and the predictions, recommendations on design modifications will be provided.

\section{ACKNOWLEDGEMENTS}

This work was performed as part of the Equipment Safety Research Program sponsored by the Office of Research and Development of the Federal Railroad Administration. The Volpe Center planned, monitored, and evaluated the research. TIAX and its subcontractors developed and evaluated the component designs. The authors appreciate the support and guidance offered by Kevin Kesler, Chief of the Equipment and Operating Practices Division, and David Tyrell, the Crashworthiness Team Leader at the Volpe Center. The authors would like to thank Gabriel Amar of Taylor Raynauld Amar \& Associates for his contribution to the contract effort. A CAD model of an MP40 locomotive was provided by MotivePower. Drawings of the freight car were provided by TrinityRail.

\section{REFERENCES}

[1] Tyrell, D., Severson, K., Marquis, B., Martinez, E., Mayville, R., Rancatore, R., Stringfellow, R., Hammond, R., Perlman, A.B., "Locomotive Crashworthiness Design Modifications Study," Proceedings of the 1999 IEEE/ASME Joint Railroad Conference, Institute of Electrical and Electronics Engineers, Catalog Number 99CH36340, 1999.

[2] Mayville, R., Stringfellow, R., Johnson, K., Landrum, S., "Crashworthiness Design Modifications for Locomotive and Cab Car Anticlimbing Systems," US Department of Transportation, DOT/FRA/ORD-03/05, February 2003.

[3] Llana, P., Stringfellow, R., "Preliminary Development of Locomotive Crashworthy Components," American Society of Mechanical Engineers, Paper No. JRC201156104, March 2011.

[4] The American Public Transportation Association, APTA SS-C\&S-034-99, Rev 2, Standard for the Design and Construction of Passenger Railroad Rolling Stock”, 2006.

[5] Association of American Railroads, AAR S-580 Standard, "Locomotive Crashworthiness Requirements," adopted December 2004, revised 2008.

[6] Code of Federal Regulations, Title 49, Part 229, "Railroad Locomotive Safety Standards".

[7] The American Public Transportation Association, APTA RP-C\&S-XXX, Recommended Practice for Push-back Couplers in Passenger Rail Equipment, draft as of 7/1/08.

[8] Mayville, R., Stringfellow, R., and Martinez, E., "Development of Conventional Passenger Cab Car End Structure Designs for Full Scale Testing.” U.S. Department of Transportation, DOT/FRA/ORD-06/20, December 2006.

This material is declared a work of the U.S. Government and is not subject to copyright protection in the United States. Approved for public release; distribution is unlimited. 